\title{
OPEN Vitamin D oral intermittent treatment (DO IT) study, a randomized clinical trial with individual loading regimen
}

Jean-Pierre Rothen ${ }^{1 凶}$, Jonas Rutishauser ${ }^{2}$, Philipp N. Walter ${ }^{3}$, Kurt E. Hersberger ${ }^{1}$ \& Isabelle Arnet $^{1}$

Comparison of several regimens of oral vitamin D including an individually calculated loading regimen with the aim of achieving serum values $>75 \mathrm{nmol} / \mathrm{l}$. Interventional, randomized, 3-arm study in vitamin D-deficient outpatients. Participants were allocated to supplementation of 24,000 IU vitamin D monthly over three months, using either a monthly drinking solution (Vi-De 3) or capsule $\left(D_{3}\right.$ VitaCaps), or an individualized loading regimen with the capsules taken weekly. For the loading regimen, the cumulative dose was calculated according to baseline 25 -hydroxy-vitamin $D(25(\mathrm{OH})$ D) serum value and body weight. Main inclusion criteria were age $\geq 18$ years and $25(\mathrm{OH}) \mathrm{D}$ serum concentration $<50 \mathrm{nmol} / \mathrm{l}$. The primary outcome was $25(\mathrm{OH}) \mathrm{D}$ serum concentration one week after treatment termination. Secondary endpoints were patient's preferences and adverse events. Full datasets were obtained from 52 patients. Mean 25(OH)D values were statistically significant higher after a loading regimen compared to a monthly administration of $24,000 \mathrm{IU}$ vitamin $\mathrm{D}(76.4 \pm 15.8 \mathrm{vs}$ $61.4 \pm 10.8 \mathrm{nmol} / \mathrm{l} ; \mathrm{p}<0.01)$. All patients treated with the loading regimen reached sufficient $25(\mathrm{OH}) \mathrm{D}$ values $>50 \mathrm{nmol} / \mathrm{l}$. Serum $25(\mathrm{OH}) \mathrm{D}$ values $>75 \mathrm{nmol} / \mathrm{l}$ were observed more frequently in patients taking the loading regimen ( $47 \%$ vs $11 \%$ drinking solution vs $12 \%$ capsules). Vitamin D-related adverse effects did not occur in any treatment groups. Capsules were preferred by $\mathbf{8 8 . 5 \%}$ of the patients. Compared to treatments with monthly intake of $24,000 \mathrm{IU}$ vitamin D, the intake of an individually calculated weekly loading regimen was able to raise serum concentrations $>50 \mathrm{nmol} / \mathrm{l}$ in all cases within a safe range.

\author{
Abbreviations \\ 25(OH)D 25-Hydroxy-vitamin D \\ FCN Swiss federal commission of nutrition \\ IoM Institute of medicine, now national academy of medicine
}

Vitamin D (cholecalciferol) insufficiency corresponding to serum 25-hydroxy-vitamin D (25(OH)D) concentrations $<50 \mathrm{nmol} / \mathrm{l}$ occurs frequently, especially during the winter period ${ }^{1,2}$ and in elderly people who can only synthesize reduced amounts of vitamin D in their skin $^{3}$. Other risk factors include reduced UV-B effectiveness in dark skin, overweight, lack of exercise, and underexposure to sunlight due to cultural or religious dress codes ${ }^{4-7}$. The serum concentration is considered the most significant indicator for vitamin D storage, with $25(\mathrm{OH}) \mathrm{D}$ values $<25 \mathrm{nmol} / \mathrm{l}$ indicating a deficiency, $25-50 \mathrm{nmol} / \mathrm{l}$ insufficiency, and values $>50 \mathrm{nmol} / \mathrm{l}$ sufficiency ${ }^{8}$. Optimal values are $>75 \mathrm{nmol} / \mathrm{l}^{9-11}$, without exact definitions of the upper reference value ${ }^{12}$.

Vitamin D can be supplemented at every age for therapeutic or prophylactic purposes. However, dosage recommendations differ. The US Institute of Medicine (IoM) recommends a daily intake of 600 IU vitamin D for adults aged 19-59 years, 800 IU for those aged $>60$ years and 1,500-2,000 IU for those with severe deficiency ${ }^{13}$. The maximum tolerable amount according to the IoM, the European Food Safety Authority and the Swiss Federal Commission of Nutrition (FCN) is 4,000 IU vitamin D per day ${ }^{13-15}$. The upper limit for adults according to the Endocrine Society Clinical Practice Guideline is 10,000 IU vitamin D per day ${ }^{12}$.

${ }^{1}$ Pharmaceutical Care Research Group, Department of Pharmaceutical Sciences, University of Basel, Petersplatz 14, Postfach 2148, 4001 Basel, Switzerland. ${ }^{2}$ Clinical Trial Unit, University Hospital of Basel, Kantonsspital Baden, Basel, Switzerland. ${ }^{3}$ Institute of Laboratory Medicine, Solothurner Spitäler, Switzerland. ${ }^{\varpi}$ email: jp.rothen@ unibas.ch 


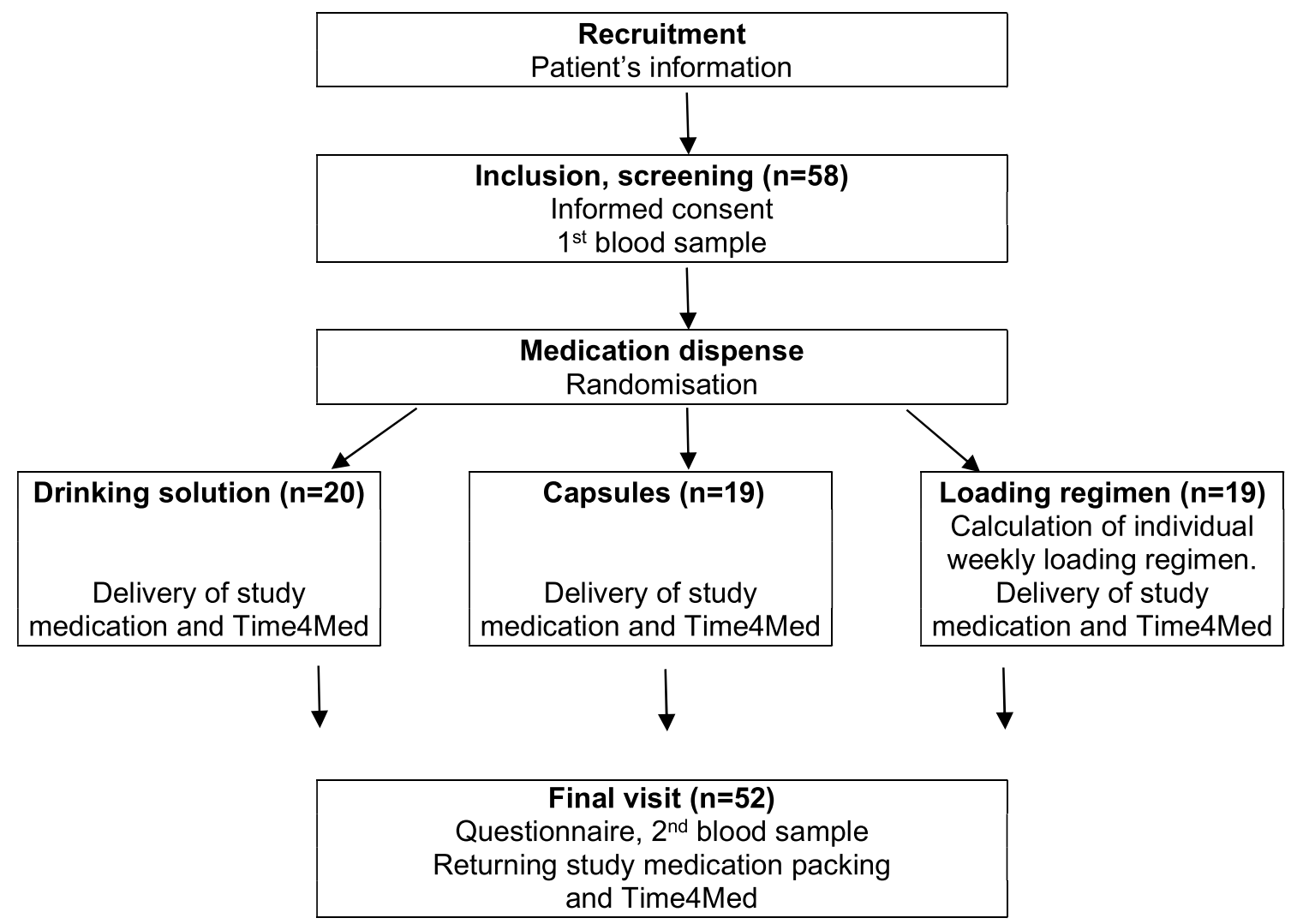

Figure 1. Study design: Design of the study assigning patients with a vitamin D insufficiency at screening $(25(\mathrm{OH}) \mathrm{D}<50 \mathrm{nmol} / \mathrm{l})$ to a 3-month intake of vitamin D as monthly drinking solution; monthly capsules or weekly loading regimen for an individually calculated period (mean 9.9, range 6-13 weeks). Adherence was monitored with the small device Time4Med.

Due to its half-life of about 2 months ${ }^{16}$, the intermittent weekly or monthly intake of cumulative doses of cholecalciferol achieves identical $25(\mathrm{OH}) \mathrm{D}$ serum values compared to corresponding daily dosage $\mathrm{e}^{17-19}$ at steady state. A loading dose regimen based on body weight and baseline $25(\mathrm{OH}) \mathrm{D}$ values has recently been suggested to initiate substitution and obtain rapid correction of vitamin D deficiency ${ }^{9}$. A formula for a loading regimen has been proposed with doses following the recommendations of the IoM and the $\mathrm{FCN}^{20}$. Its practicality has been confirmed at doses exceeding the recommendations ${ }^{21}$.

In earlier trials comparing weekly to monthly cumulative administration of 800 IU vitamin D in liquid or solid formulation, an optimal $25(\mathrm{OH}) \mathrm{D}$ value of $>75 \mathrm{nmol} / \mathrm{l}$ was achieved only by a minority of patients after 3 or 6 months of treatment using either regimen ${ }^{22,23}$

The aims of this study were a) to investigate whether a loading regimen without exceeding the maximum dosage of 4,000 IU vitamin D per day as recommended by the IoM ${ }^{13}$ and the $\mathrm{FCN}^{15}$ would lead to mean $25(\mathrm{OH})$ $\mathrm{D}$ values that are higher than after a monthly vitamin $\mathrm{D}$ treatment and $\mathrm{b}$ ) to compare two monthly vitamin $\mathrm{D}$ treatment regimens of different formulations (liquid and solid).

\section{Methods}

Study hypothesis. A weekly loading regimen with capsules containing 24,000 IU vitamin D during an individually calculated duration will be able to raise mean $25(\mathrm{OH}) \mathrm{D}$ levels higher than a monthly administration; the monthly substitution of 24,000 IU vitamin D either as capsules or as alcoholic drinking solution will lead to $25(\mathrm{OH}) \mathrm{D}$-values in the same range.

Setting. This was an interventional, randomized, 3-arm study using two formulations of vitamin D. The liquid formulation was Vi-De 3 monthly dose bottle (Wild \& Co. Inc., 4132 Muttenz, Switzerland; 24,000 IU/5 ml in $65 \%$ alcoholic solution). The solid formulation was newly developed gelatin-free soft capsules (24,000 IU/capsule; $\mathrm{D}_{3}$ VitaCaps). Patients were administered 24,000 IU vitamin D monthly as drinking solution (group drinking solution) or as monthly capsules (group capsules), or as a loading regimen (group loading regimen) (Fig. 1). The loading regimen consisted of the weekly intake of one 24,000 IU vitamin D capsule without initial bolus. The number of weeks was calculated as follows: $40^{\star}(100-25(\mathrm{OH}) \mathrm{D} \text { baseline concentration }[\mathrm{nmol} / \mathrm{l}])^{\star}$ body weight $[\mathrm{kg}] / 24,000$ using the formula adapted from ${ }^{20}$. Numbers were rounded to the next entire number of capsules. 


\begin{tabular}{|l|l|l|l|l|}
\hline & All $(\mathbf{n}=\mathbf{5 8})$ & Drinking solution $(\mathbf{n}=\mathbf{2 0})$ & Capsules $(\mathbf{n}=\mathbf{1 9 )}$ & Loading regimen $(\mathbf{n}=\mathbf{1 9 )}$ \\
\hline $\begin{array}{l}\text { Age } \text { [years] } \\
\mathrm{m} \pm \mathrm{s}(\mathrm{range})\end{array}$ & $\begin{array}{l}49.0 \pm 17.6 \\
(19-89)\end{array}$ & $\begin{array}{l}47.3 \pm 19.6 \\
(19-89)\end{array}$ & $\begin{array}{l}51.3 \pm 18.1 \\
(23-82)\end{array}$ & $\begin{array}{l}48.6 \pm 15.4 \\
(19-82)\end{array}$ \\
\hline Male $[\mathrm{n}]$ & 25 & 8 & 7 & 10 \\
\hline Female $[\mathrm{n}]$ & 33 & 12 & 12 & 9 \\
\hline $\begin{array}{l}\text { Height }[\mathrm{m}] \\
\mathrm{m} \pm \mathrm{s}(\text { range })\end{array}$ & $\begin{array}{l}1.72 \pm 0.09 \\
(1.50-1.89)\end{array}$ & $\begin{array}{l}1.72 \pm 0.11 \\
(1.50-1.89)\end{array}$ & $\begin{array}{l}1.70 \pm 0.08 \\
(1.53-1.84)\end{array}$ & $\begin{array}{l}1.72 \pm 0.09 \\
(1.59-1.88)\end{array}$ \\
\hline $\begin{array}{l}\text { Weight }[\mathrm{kg}] \\
\mathrm{m} \pm \mathrm{s}(\text { range })\end{array}$ & $\begin{array}{l}80.3 \pm 18.0 \\
(43-124)\end{array}$ & $\begin{array}{l}78.5 \pm 17.7 \\
(43-124)\end{array}$ & $\begin{array}{l}75.7 \pm 12.0 \\
(54-99)\end{array}$ & $\begin{array}{l}84.9 \pm 22.2 \\
(53-120)\end{array}$ \\
\hline $\begin{array}{l}\text { BMI }\left[\mathrm{kg} / \mathrm{m}^{2}\right] \\
\mathrm{m} \pm \mathrm{s}(\mathrm{range})\end{array}$ & $\begin{array}{l}27.2 \pm 5.4 \\
(19.1-41.0)\end{array}$ & $\begin{array}{l}26.4 \pm 5.4 \\
(19.1-41.0)\end{array}$ & $\begin{array}{l}26.2 \pm 3.3 \\
(22.0-32.6)\end{array}$ & $\begin{array}{l}28.4 \pm 6.7 \\
(19.4-40.1)\end{array}$ \\
\hline Comedication $[\mathrm{n}] \mathrm{m} \pm \mathrm{s}$ (range) & $\begin{array}{l}1.6 \pm 1.7 \\
(0-6)\end{array}$ & $\begin{array}{l}1.5 \pm 1.9 \\
(0-6)\end{array}$ & $\begin{array}{l}1.8 \pm 1.7 \\
(0-6)\end{array}$ & $\begin{array}{l}1.5 \pm 1.6 \\
(0-6)\end{array}$ \\
\hline
\end{tabular}

Table 1. Patient's characteristics included to the study $(n=58)$.

Patients and outcome measures. Six general practitioners in and near Basel (Switzerland) who were experienced in performing research studies participated in this study. Patients were enrolled in an outpatient setting during routine medical visits. Inclusion criteria were age $\geq 18$ years and vitamin $\mathrm{D}$ insufficiency (serum $25(\mathrm{OH}) \mathrm{D}$ concentration $<50 \mathrm{nmol} / \mathrm{l})$. Exclusion criteria were hypercalcaemia and nephrolithiasis. The primary outcome measure was $25(\mathrm{OH}) \mathrm{D}$ serum concentration. Secondary outcomes were patients' preferences, adherence and adverse events.

Randomization. Patients were randomly allocated to one of the three treatment groups using 1:1:1 block randomization with block size 6 or 9 . Identical plain envelopes containing 2 to 3 case report forms per group were placed manually in random order in plastic boxes. Physicians took one case report forms per patient from a plastic box. Both patients and recruiting physicians were aware of treatment allocation. Patients were asked to return packings at the final study visit.

Study visits, laboratory measurements and questionnaires. Serum concentrations of 25(OH)D (reference range 50-250 nmol/l), intact parathyroid hormone (reference range 1.59-12.0 pmol/l), total calcium (reference range $2.10-2.55 \mathrm{mmol} / \mathrm{l}$ ), phosphate (reference range $0.74-1.52 \mathrm{mmol} / \mathrm{l}$ ), alkaline phosphatase (reference range 40-150 U/1), and creatinine were measured at screening and one week after termination the study medication, The Institute of Laboratory Medicine of the Solothurn Hospitals performed the analysis using the Architect analysis system by Abbott AG, CH-6341 Baar.

The physicians asked the patient's preferred date of intake and wrote it directly on the packings (for example: $10 \mathrm{Oct} / 10 \mathrm{Nov} / 10 \mathrm{Dec})$. Patients were provided with the Time4Med smart card ${ }^{24}$, a device for the electronic assessment of adherence which registered date and time of study medication intake upon patient activation.

Patients were not to travel south of $35^{\circ}$ latitude during the trial. Study visits were medication dispense and the final visit. During the latter, five questions with dichotomous answer options were asked addressing the following items: 1) Did you stay during the treatment south of latitude 35? [Yes, No]. 2) Have you noticed any listed unexpected events? [Yes (please specify), No]. 3) Have you noticed any other unexpected events? [Yes (please specify), No]. 4) How did you manage to take your medication in the past 3 months? [well, poorly]. 5) Do you prefer the intake of $24^{\prime} 000$ IU vitamin D as drinking solution or as capsules?

Statistical analysis. Visual examination of the returned medication packings was performed. Empty bottles or empty blister cavities were defined as adherence. Time4Med smart card data were used to calculate adherence as \% predicted ([number of doses taken / number of doses prescribed) $\left.{ }^{\star} 100\right)^{24}$. Sample size was calculated according to the assumed difference in the mean $25(\mathrm{OH}) \mathrm{D}$ serum values between the patient groups with monthly intake of 24,000 IU cholecalciferol and the patient group with loading regimen. We assumed that $25(\mathrm{OH}) \mathrm{D}$ serum value reach $55 \pm 18 \mathrm{nmol} / \mathrm{l}$ following a monthly treatment ${ }^{22}$, and $75 \mathrm{nmol} / \mathrm{l}$ following the loading regimen, which corresponds to a difference of $20 \mathrm{nmol} / \mathrm{l}$. Thus, we need 37 patients ( 17 patients per group +3 drop-outs) to detect whether the stated difference exists between the two means with a power of $90 \%$, a significance level at $5 \%$, and a drop-out rate of $10 \%{ }^{25}$.

The statistical evaluation was carried out using SPSS (IBM, version 27). Values are presented as mean \pm standard deviations (s), median with quartiles and as percentages, where appropriate. Mann-Whitney U-test was used to compare numerical variables between the groups. Mean $25(\mathrm{OH}) \mathrm{D}$-values at screening and at the final visit were compared using the Wilcoxon test. p-values $<0.05$ were considered significant.

This study was approved by the local ethics committee of the Northwestern and Central Switzerland (Ethikkommission Nordwest- und Zentralschweiz, ID 2009-00749 from 19/06/2019), from the Swiss Agency for Therapeutic Products Swissmedic (ID 2019DR1129 from 04/10/2019) and was registered in the public register clinicaltrials.gov (ID NCT03920150, first posted date-18/04/2019). The protocol was performed in accordance with the relevant guidelines and regulations. All participants provided informed consent. 


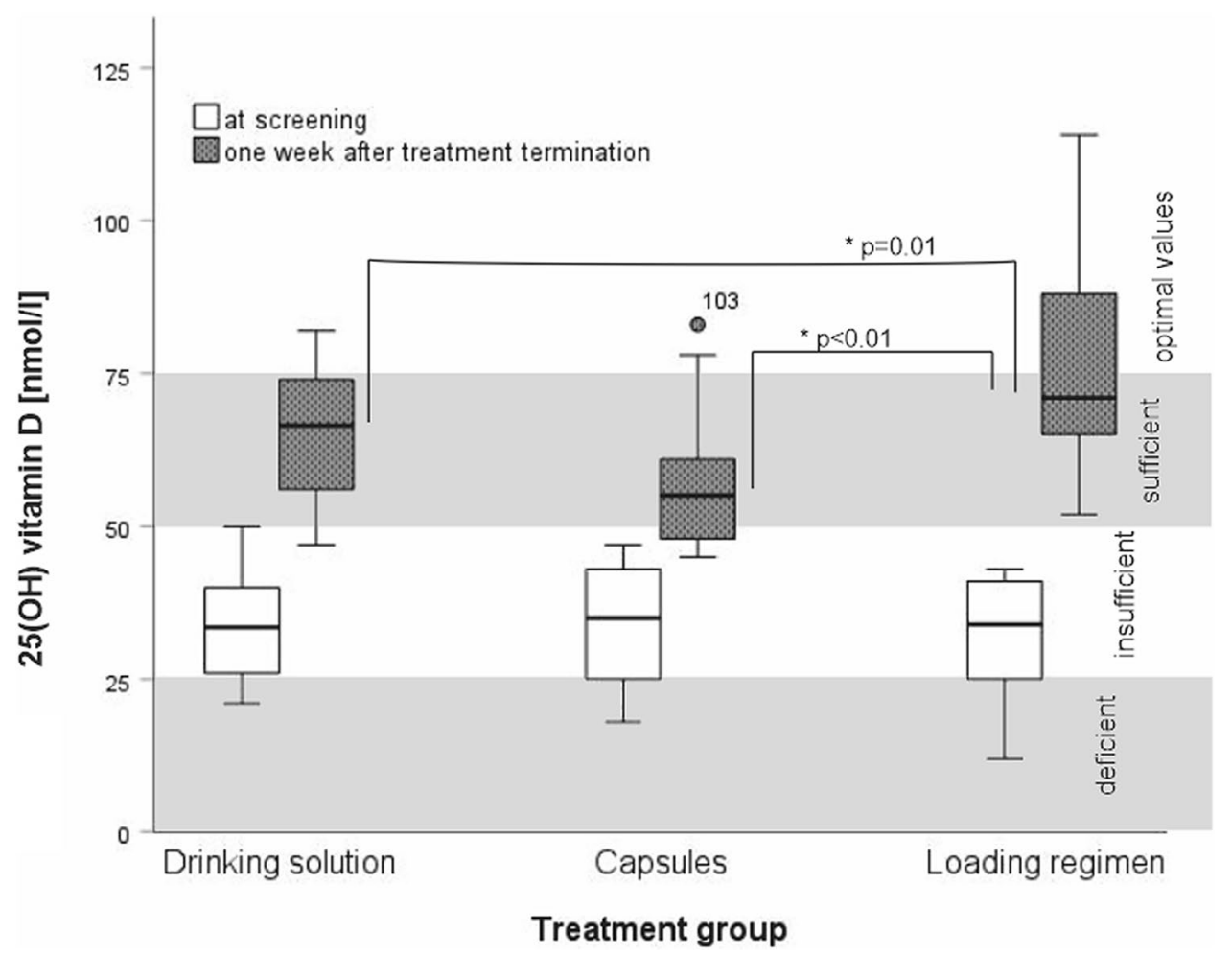

Figure 2. Representation of median $25(\mathrm{OH}) \mathrm{D}$ values at screening (white boxes) and one week after treatment termination (grey boxes) per treatment groups (Drinking solution, Capsules, and Loading regimen) as Whisker boxplot. Significant differences are marked with *.

\begin{tabular}{|l|l|l|l|}
\hline Participant code & Treatment group & Unexpected event & Severity/Seriousness \\
\hline KD16 & Drinking solution & Facial acne & Mild, non-serious \\
\hline SE56 & \multirow{2}{*}{ Capsules } & Recurrent light neck scratching and headaches for 4 weeks & Mild, non-serious \\
\cline { 4 - 4 } & & Diarrhoea once & Mild, non-serious \\
\hline PP72 & \multirow{2}{*}{ Loading regimen } & Flu-like infection, 3 days of cough and fever & Mild, non-serious \\
\cline { 4 - 4 } & & Occasional dizziness after taking study medication & Mild, non-serious \\
\cline { 3 - 4 } & & Pancreatitis & Severe, serious \\
\hline KD04 & &
\end{tabular}

Table 3. Reported unexpected events at final visit.

capsules registered only one intake electronically instead of three, their taking adherence according visual assessment was $100 \%$.

\section{Discussion}

The administration of an individually calculated loading regimen of weekly 24,000 IU vitamin D enabled to reach significantly higher $25(\mathrm{OH}) \mathrm{D}$ values compared to the monthly administration of a cumulative daily dose of 800 IU vitamin D. All patients in this latter group had sufficient, and half of them optimal $25(\mathrm{OH}) \mathrm{D}$ levels. There was no statistical difference in the increase of vitamin D levels after supplementation of 24,000 IU monthly between patients taking the drinking solution and those on oily soft-capsules. Our results thus show no difference between the newly developed capsules and the drinking solution. In both groups, a majority of the patients achieved sufficient $25(\mathrm{OH}) \mathrm{D}$ values, and only $12 \%$ reached the optimal range. This result is in line with previous studies $^{22,23,26}$ and indicates that the capsules are suitable for use in general medical practice. Additionally, patients' preferences were unequivocally in favour of capsules.

The toxic range was not reached by far. This demonstrates that the loading dose regimen more frequently leads to optimal $25(\mathrm{OH}) \mathrm{D}$ serum values $(>75 \mathrm{nmol} / \mathrm{l})$ without exceeding the maximum dosage of $4,000 \mathrm{IU}$ vitamin D per day.

To calculate the loading regimen, we adapted a published formula ${ }^{20}$. Our equation subtracts the baseline 25(OH)D value from $100 \mathrm{nmol} / \mathrm{l}$, whereas the original formula uses $75 \mathrm{nmol} / \mathrm{l}$. The increase is justified by the fact that in the original publication, only $76 \%$ of the patients achieved a serum $25(\mathrm{OH}) \mathrm{D}$ level $>50 \mathrm{nmol} / \mathrm{l}$, and $48 \%$ of them achieved a serum $25(\mathrm{OH}) \mathrm{D}$ level $>75 \mathrm{nmol} / \mathrm{I}^{20}$. Especially, in the group obtaining a cumulative dose 
of $200^{\prime} 000$ IU vitamin D which is the closest to our regimen, the mean $25(\mathrm{OH}) \mathrm{D}$ increased to $87.7 \pm 26.9 \mathrm{nmol} / \mathrm{l}$. This overall result leaves room for improvement. Thus, in analogy to a dose-finding study, we selected $100 \mathrm{nmol} / \mathrm{l}$ as the next higher target value in the formula to be susceptible to increase the serum $25(\mathrm{OH}) \mathrm{D}$ values consistently to sufficient levels. With our adjustment, we obtained $100 \%$ of the serum $25(\mathrm{OH}) \mathrm{D}$ values $>50 \mathrm{nmol} / \mathrm{l}$ and $47 \%$ of them $>75 \mathrm{nmol} / \mathrm{l}$, which matches our expected target values.

Our loading regimen includes no loading dose, but 24,000 IU single doses. This corresponds approximately to the upper level of vitamin $\mathrm{D}$ that is physiologically produced in the $\operatorname{skin}^{27}$. Especially a paradox response of single bolus greater than 100,000 IU vitamin D is currently discussed as this may lead to intracellular deficiency ${ }^{28}$. Thus and according to the most recent literature, we claim that our loading regimen with its adapted formula and the strength of 24,000 IU vitamin D represents an appropriate regimen to effectively, safely and rapidly supplement vitamin D.

As expected, the doses administered in the study were not linked to adverse drug reaction, as the reported adverse events were probably not related to the administration of the study medication. Further, no pathologic laboratory values were observed that could be attributed to the administration of vitamin D. Especially, no patient developed hypercalcaemia. Overdosage has not been observed even when using the loading regimen.

The taking adherence was high compared to other adherence trials ${ }^{29}$ performed in the similar setting of supplementation. This might be attributed to highly motivated study participants who were recruited by their general practitioner or to a large acceptance of vitamin D supplementation in the general population. In addition, noting the exact days for the medication intake on the packings may have acted like a reminder and facilitated a regular intake and thus, a high adherence. Compared to affixing a label with a dosing instruction (such as "Take a capsule once monthly"), the instruction was an individualized consensus (such as "3 OCT / 3 NOV / 3 DEC") with the patient, resembling to shared decision-making ${ }^{30}$.

The number of six withdrawals $(10.3 \%)$ seems high. However, five patients missed their final visit, which is probably linked to the lockdown installed during the COVID pandemic.

Our study has several strengths. First, the upper dose limit as defined by the FCN dosage recommendations was respected, also in the loading regimen group. Second, we included only patients with a confirmed vitamin $\mathrm{D}$ insufficiency with $25(\mathrm{OH}) \mathrm{D}$ values $<50 \mathrm{nmol} / \mathrm{l}$. Third, preliminary calculation with the loading regimen formula enabled us to anticipate the study duration at approximately 3 months. Thus, a similar study duration was obtained for each group, rendering our results more robust. Finally, our results can be generalized, because the six general practitioners are very diverse and represent the usual internal medical situations.

We acknowledge some limitations. First, the study lasted 3 months for the monthly regimens and up to 13 weeks with the loading regimen, and not the whole winter half-year. This allowed us to extend the recruitment period. Second, the number of study patients is small. Nevertheless, our findings correspond to those of other studies.

To conclude, a supplementation regimen with capsules containing 24,000 IU vitamin D over an individually calculated duration leads to sufficient values $(>50 \mathrm{nmol} / \mathrm{l})$ in all patients and to optimal values $(>75 \mathrm{nmol} / \mathrm{l})$ in approximately $50 \%$ of the patients. Prescribers should take into account patient's preference to support a shared decision-making process when prescribing a medication such as vitamin D that exists in different medication formulation.

Received: 13 April 2021; Accepted: 24 August 2021

Published online: 21 September 2021

\section{References}

1. Adams, J. S. \& Hewison, M. Update in vitamin D. J. Clin. Endocrinol. Metab. 95, 471-478 (2010).

2. Quarenghi, M. C. et al. Vitamin D deficiency in the sunny corner of Switzerland. Praxis 106, 1323-1330 (2017).

3. Hintzpeter, B., Mensink, G. B., Thierfelder, W., Muller, M. J. \& Scheidt-Nave, C. Vitamin D status and health correlates among German adults. Eur. J. Clin. Nutr. 62, 1079-1089 (2008).

4. Kaddam, I. M. et al. Prevalence of vitamin D deficiency and its associated factors in three regions of Saudi Arabia. Saudi Med. J. 38, 381-390 (2017).

5. Abboud, M., Rybchyn, M. S., Rizk, R., Fraser, D. R. \& Mason, R. S. Sunlight exposure is just one of the factors which influence vitamin D status. Photochem. Photobiol. Sci. 16, 302-313 (2017).

6. Zittermann, A., Ernst, J. B., Gummert, J. F. \& Borgermann, J. Vitamin D supplementation, body weight and human serum 25-hydroxyvitamin D response: A systematic review. Eur. J. Nutr. 53, 367-374 (2014).

7. Hardi, I., Reinhard, S., Conzelmann, M., Kressig, R. W. \& Bridenbaugh, S. A. Vitamin D level in employees of a Swiss University geriatric hospital. Praxis 107, 633-640 (2018).

8. Braegger, C. et al. Vitamin D in the healthy European paediatric population. J. Pediatr. Gastroenterol. Nutr. 56, 692-701 (2013).

9. Dalle Carbonare, L., Valenti, M. T., Del Forno, F., Caneva, E. \& Pietrobelli, A. Vitamin D: Daily vs monthly use in children and elderly-What is going on?. Nutrients $\mathbf{9 , 2}$ (2017).

10. Pludowski, P. et al. Practical guidelines for the supplementation of vitamin D and the treatment of deficits in Central Europe-recommended vitamin D intakes in the general population and groups at risk of vitamin D deficiency. Endokrynol. Pol. 64, 319-327 (2013).

11. Amrein, K. et al. Vitamin D deficiency 2.0: an update on the current status worldwide. Eur. J. Clin. Nutr. 2, 2 (2020).

12. Holick, M. F. et al. Evaluation, treatment, and prevention of vitamin D deficiency: An endocrine society clinical practice guideline. J. Clin. Endocrinol. Metab. 96, 1911-1930 (2011).

13. Ross, A. C. et al. The 2011 report on dietary reference intakes for calcium and vitamin D from the Institute of Medicine: What clinicians need to know. J. Clin. Endocrinol. Metab. 96, 53-58 (2011).

14. EFSA. Scientific opinion on the tolerable upper intake level of vitamin D. EFSA J. 10, 2 (2012).

15. Bischoff-Ferrari, H., et al. Empfehlungen der Eidgenössichen Ernährungskommission zur Vitamin-D-Zufuhr für die Schweizer Bevölkerung. in Swiss Medical Forum, Vol. 12 775-778 (EMH Media, 2012).

16. Vieth, R. The pharmacology of vitamin D, including fortification strategies. Vitamin D 2, 995-1015 (2005)

17. Noe, S. et al. Cholecalciferol 20000 IU once weekly in HIV-positive patients with low vitamin D levels: Result from a cohort study. J. Int. Assoc. Provid. AIDS Care 16, 315-320 (2017). 
18. Ish-Shalom, S. et al. Comparison of daily, weekly, and monthly vitamin D3 in ethanol dosing protocols for two months in elderly hip fracture patients. J. Clin. Endocrinol. Metab. 93, 3430-3435 (2008).

19. Takacs, I. et al. Randomized clinical trial to comparing efficacy of daily, weekly and monthly administration of vitamin D3. Endocrine 55, 60-65 (2017).

20. van Groningen, L. et al. Cholecalciferol loading dose guideline for vitamin D-deficient adults. Eur. J. Endocrinol. 162, 805-811 (2010).

21. Wijnen, H., Salemink, D., Roovers, L., Taekema, D. \& de Boer, H. Vitamin D supplementation in nursing home patients: Randomized controlled trial of standard daily dose versus individualized loading dose regimen. Drugs Aging 32, 371-378 (2015).

22. Rothen, J. P., Rutishauser, J., Walter, P. N., Hersberger, K. E. \& Arnet, I. Oral intermittent vitamin D substitution: Influence of pharmaceutical form and dosage frequency on medication adherence: A randomized clinical trial. BMC Pharmacol. Toxicol. 21, $51(2020)$.

23. Cavalier, E., Fache, W. \& Souberbielle, J. C. A randomised, double-blinded, placebo-controlled, parallel study of vitamin D3 supplementation with different schemes based on multiples of 25,000 IU doses. Int. J. Endocrinol. 2013, 327265 (2013).

24. Arnet, I., Rothen, J. P., Albert, V. \& Hersberger, K. E. Validation of a novel electronic device for medication adherence monitoring of ambulatory patients. Pharmacy 7, 2 (2019).

25. Sample size calculator. (ClinCalc.com).

26. Aspray, T. J. et al. Randomized controlled trial of vitamin D supplementation in older people to optimize bone health. Am. J. Clin. Nutr. 109, 207-217 (2019).

27. Wacker, M. \& Holick, M. F. Sunlight and Vitamin D: A global perspective for health. Dermato-Endocrinol. 5, 51-108 (2013).

28. Griffin, G. et al. Perspective: Vitamin D supplementation prevents rickets and acute respiratory infections when given as daily maintenance but not as intermittent bolus: implications for COVID-19. Clin. Med. 2, 2 (2021).

29. Brorsson, A. L., Nordin, K. \& Ekbom, K. Adherence to vitamin supplementation recommendations in youth who have undergone bariatric surgery as teenagers: a mixed methods study. Obes. Surg. 2, 2 (2020).

30. Schoenthaler, A., Rosenthal, D. M., Butler, M. \& Jacobowitz, L. Medication adherence improvement similar for shared decisionmaking preference or longer patient-provider relationship. J. Am. Board Fam. Med. 31, 752-760 (2018).

\section{Acknowledgements}

We thank the investigators Dr. med. Karen Delport, PD Dr. med. Stefan Erb, Dr. med. Gilliane Petitjean Schelker, Dr. med. Anja Sabine Plack, and Dr. med. Madeleine Rothen who, beyond their daily task as general practitioners, are also dedicated to research. The study medication was provided free of charge by Nutrimed. Laboratory analyses were kindly provided by the Institute of Laboratory Medicine, Solothurn Hospitals in Olten, Switzerland. Funding of publication by the "Publication Fund of University of Basel for Open Access".

\section{Author contributions}

J.P.R. and I.A. developed the study design, collected and analyzed the data and drafted the first version of the manuscript. J.R. participated as clinical advisor of the study and included patients; P.W. participated in investigation and methodology; K.H. participated in funding and supervised the trial. All authors edited and approved the final manuscript.

\section{Competing interests}

Jean-Pierre Rothen is an employee of Nutrimed Ltd. All other authors declare that they have no competing interests.

\section{Additional information}

Correspondence and requests for materials should be addressed to J.-P.R.

Reprints and permissions information is available at www.nature.com/reprints.

Publisher's note Springer Nature remains neutral with regard to jurisdictional claims in published maps and institutional affiliations.

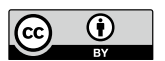

Open Access This article is licensed under a Creative Commons Attribution 4.0 International License, which permits use, sharing, adaptation, distribution and reproduction in any medium or format, as long as you give appropriate credit to the original author(s) and the source, provide a link to the Creative Commons licence, and indicate if changes were made. The images or other third party material in this article are included in the article's Creative Commons licence, unless indicated otherwise in a credit line to the material. If material is not included in the article's Creative Commons licence and your intended use is not permitted by statutory regulation or exceeds the permitted use, you will need to obtain permission directly from the copyright holder. To view a copy of this licence, visit http://creativecommons.org/licenses/by/4.0/.

(C) The Author(s) 2021 